\title{
Ozone zonal asymmetry and planetary wave characterization during Antarctic spring
}

\author{
I. Ialongo, V. Sofieva, N. Kalakoski, J. Tamminen, and E. Kyrölä \\ Finnish Meteorological Institute, Earth Observation Unit, Helsinki, Finland \\ Correspondence to: I. Ialongo (iolanda.ialongo@fmi.fi) \\ Received: 3 October 2011 - Published in Atmos. Chem. Phys. Discuss.: 8 December 2011 \\ Revised: 1 March 2012 - Accepted: 2 March 2012 - Published: 8 March 2012
}

\begin{abstract}
A large zonal asymmetry of ozone has been observed over Antarctica during winter-spring, when the ozone hole develops. It is caused by a planetary wave-driven displacement of the polar vortex. The total ozone data by OMI (Ozone Monitoring Instrument) and the ozone profiles by MLS (Microwave Limb Sounder) and GOMOS (Global Ozone Monitoring by Occultation of Stars) were analysed to characterize the ozone zonal asymmetry and the wave activity during Antarctic spring. Both total ozone and profile data have shown a persistent zonal asymmetry over the last years, which is usually observed from September to mid-December. The largest amplitudes of planetary waves at $65^{\circ} \mathrm{S}$ (the perturbations can achieve up to $50 \%$ of zonal mean values) is observed in October. The wave activity is dominated by the quasi-stationary wave 1 component, while the wave 2 is mainly an eastward travelling wave. Wave numbers 1 and 2 generally explain more than the $90 \%$ of the ozone longitudinal variations. Both GOMOS and MLS ozone profile data show that ozone zonal asymmetry covers the whole stratosphere and extends up to the altitudes of 60-65 km. The wave amplitudes in ozone mixing ratio decay with altitude, with maxima (up to $50 \%$ ) below $30 \mathrm{~km}$.

The characterization of the ozone zonal asymmetry has become important in the climate research. The inclusion of the polar zonal asymmetry in the climate models is essential for an accurate estimation of the future temperature trends. This information might also be important for retrieval algorithms that rely on ozone a priori information.
\end{abstract}

\section{Introduction}

Planetary waves influence the atmospheric circulations and affect the spatial distribution and time variations of trace gases in the stratosphere (e.g. Mechoso et al., 1985; Holton et al., 1995). They are generated in the troposphere by thermal and orographic forcing (Andrews et al., 1987) and propagate upwards (Hartmann et al., 1984). Stratospheric planetary waves play an important role in shaping the ozone hole (e.g. Solomon, 1999; Fusco and Salby, 1999) through their impact on the polar vortex and on the Brewer-Dobson circulation (BDC). Several studies (e.g. Grytsai et al., 2005, 2007; Crook et al., 2008; Gabriel et al., 2011) have reported a large zonal asymmetry of spring-time ozone over Antarctica. Hio and Yoden (2004) showed that during Antarctic winter-spring the zonal wave number 1 usually gives the main contribution to the ozone zonal asymmetry, while higher zonal wave numbers show travelling structures. The wave-driven displacement of the polar vortex moves low-ozone airmasses equatorwards up to $50^{\circ} \mathrm{S}$. Grytsai et al. (2007) have analysed the total ozone measurements by TOMS (Total Ozone Mapping Spectrometer) over Antarctica over the period 1979-2005, observing the highest zonal asymmetry ( $\sim 60$ DU spring average) at $65^{\circ} \mathrm{S}$, where the edge of the polar vortex is usually located. The ozone zonal asymmetry over Antarctica during spring is caused by the displacement of the ozone hole with respect to the pole because of planetary wave activity. In addition, ozone-rich air accumulates in the South-East sector outside the vortex as a result of the poleward transport of the BDC. 
The ozone column abundance is related to the tropopause height, which in turn is influenced by the temperature of the lower stratosphere over Antarctica, so that the tropopause raises while the stratosphere cools. Decreased total ozone is associated with lower tropopause pressure (and thus with the higher tropopause), and vice versa. Unlike the influence of tropospheric synoptic processes occurring at midlatitudes, the anti-correlation between total ozone and tropopause height over the Antarctic region has a stratospheric origin (Evtushevsky et al., 2008).

The characterization of the zonal asymmetry has become relevant in the climate research, because of its important impact on Southern Hemisphere ( $\mathrm{SH}$ ) climate when a large ozone hole is observed (Crook et al., 2008). Waugh et al. (2009) have shown that prescribing zonal-mean ozone in the climate models results in a warmer Antarctic stratosphere in comparison to a three-dimentional ozone field. As a consequence, Antarctic temperature trends are underestimated when zonal-mean ozone is prescribed. The impacts of stratospheric changes on the tropospheric circulation (i.e. summertime trends in the $\mathrm{SH}$ annular mode) are underestimated, too. Also the results achieved by Gillett et al. (2009) suggest that the inclusion of zonal asymmetries in ozone might be essential for the accurate simulation of future stratospheric temperature trends. They found a zonal mean temperature response to the ozone zonal asymmetry up to $4 \mathrm{~K}$ in the lower stratosphere.

In this paper, the ozone zonal asymmetry during the Antarctic spring over the time period 2005-2010 is characterized by using total ozone observations from the Ozone Monitoring Instrument (OMI) on board the EOS-Aura satellite. This analysis extends the results derived from TOMS data (Grytsai et al., 2007). In addition, the vertical extent of the anomaly is characterized by using ozone profiles measurements by Global Ozone Monitoring by Occultation of Stars (GOMOS) and Microwave Limb Sounder (MLS). The paper is organised as follows. The data are described in Sect. 2. In Sect. 3 the data analysis is explained. The description of the results, including the ozone zonal asymmetry and the wave activity characterization, is presented in Sect. 4 . Discussion and summary conclude the paper.

\section{Data}

\subsection{OMI total ozone}

The Ozone Monitoring Instrument (OMI) total ozone level 3 data (2005-2010) from the V8 TOMS-like algorithm (Bhartia et al., 2002) were used in this study. OMI is a DutchFinnish instrument that flies onboard NASA's EOS-Aura satellite. The OMI TOMS-like algorithm uses 2 wavelengths $(317.5 \mathrm{~nm}$ and $331.2 \mathrm{~nm}$ under most conditions, and $331.2 \mathrm{~nm}$ and $360.0 \mathrm{~nm}$ for high ozone and high solar zenith angle conditions). The longer of the two wavelengths is used to derive the surface reflectivity (or cloud fraction). The shorter wavelength, which is heavily absorbed by ozone, is used to derive total ozone. The OMI total ozone level 3 data are available at http://mirador.gsfc.nasa.gov/ with a spatial resolution of $1^{\circ} \times 1^{\circ}$. The estimated root-mean square error is $1-2 \%$, depending on solar zenith angle, aerosol amount and cloud cover (Bhartia et al., 2002).

\subsection{GOMOS ozone profiles}

GOMOS (http://envisat.esa.int/instruments/gomos) is a stellar occultation instrument, which includes UV-VIS-IR spectrometers for monitoring of ozone and a few other trace gases in the atmosphere (Bertaux et al., 2010). The details of the GOMOS retrieval from night-time UV-VIS measurements are presented in Kyrölä et al. (2010). The retrieval algorithm relies on the maximum likelihood estimates and uses a minimal amount of a priori information (i.e. it does not use a priori information about the ozone profiles in the Bayesian sense). The retrieval is stabilized by the Tikhonov regularization (Kyrölä et al., 2010; Sofieva et al., 2004; Tamminen et al., 2004), which makes the vertical resolution practically independent of angles between the orbital plane and the direction to the star. The vertical resolution (including the smoothing properties of the inversion) of GOMOS ozone profiles is $2 \mathrm{~km}$ below $30 \mathrm{~km}$ and $3 \mathrm{~km}$ above $40 \mathrm{~km}$. From night-time measurements, ozone is retrieved in the altitudes range from $\sim 10 \mathrm{~km}$ up to $\sim 100 \mathrm{~km}$.

The accuracy of the GOMOS retrievals depends on stellar magnitude and spectral class (Tamminen et al., 2010). For this study, dark-limb occultations of hot (effective temperature $\geq 6000 \mathrm{~K}$ ) and sufficiently bright (visual magnitude $<2$ ) stars were selected. The successive occultations of each star are nearly uniformly distributed in the longitudinal direction (maximum 14 occultations per day), and they are carried out approximately at the same local time. GOMOS data coverage is illustrated e.g. in Fig. 1 in Sofieva et al. (2009). The precision of individual ozone profiles is $0.5-2 \%$ in the stratosphere and $1-5 \%$ in the mesosphere (Tamminen et al., 2010).

\subsection{MLS ozone profiles}

The Microwave Limb Sounder (MLS), onboard Aura spacecraft, measures thermal microwave limb emission by the atmosphere in five spectral bands from $115 \mathrm{GHz}$ to $2.5 \mathrm{THz}$ (Waters et al., 2006). MLS scans the atmosphere from ground to $\sim 90 \mathrm{~km}$ every $24.7 \mathrm{~s}$. Scan rate is synchronized to the Aura orbit which means that it scans each orbit at essentially the same latitudes. Horizontally the profiles are spaced by $1.5^{\circ}$ great-circle angles along the orbit. The cross-track resolution is defined by the $6 \mathrm{~km}$ width of the MLS field of view. A typical MLS data coverage in the polar regions is shown e.g. in Fig. 2 of Sofieva et al. (2012). The ozone profiles are retrieved from the spectral region near $240 \mathrm{GHz}$. For 


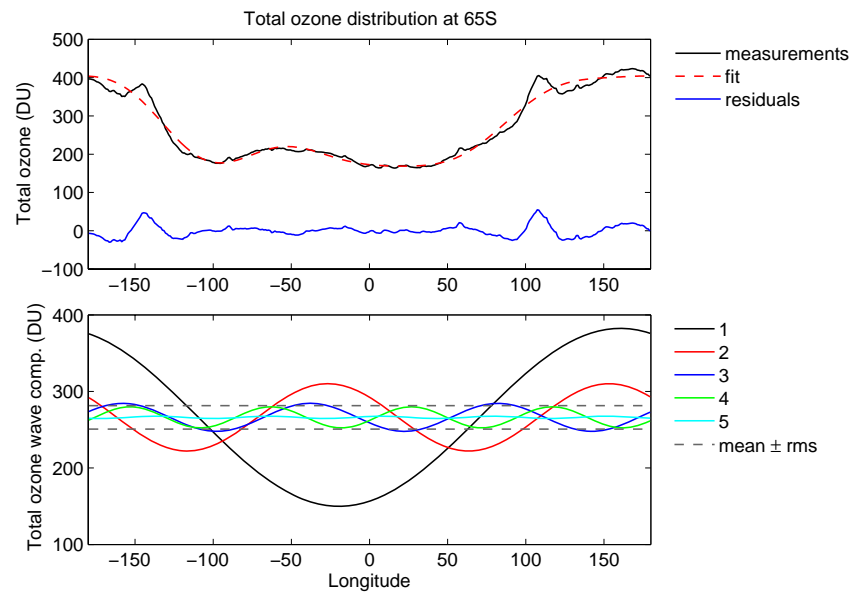

Fig. 1. The observed (black solid line - upper panel) distribution from OMI total ozone along $65^{\circ} \mathrm{S}$, compared with the modelled (red dashed line - upper panel) distribution using 1-5 wave numbers on 16 October 2010. The distribution of the residuals is also shown (blue solid line-upper panel). The spectral components of the wave number 1 to 5 are shown in the lower panel. The gray dashed lines in the lower panel indicates the mean \pm the rms of the residuals.

the description of the retrieval algorithm, see Livesey and Snyder (2004).

The vertical resolution of MLS ozone profiles is $2.5-3 \mathrm{~km}$ in the stratosphere degrading to $5.5 \mathrm{~km}$ in the lower mesosphere. Precisions range from $2-7 \%$ in the stratosphere to more than $20 \%$ in the mesosphere. Measurements are considered to be valid within the pressure range $316-0.02 \mathrm{hPa}$ $(\sim 8-75 \mathrm{~km})$. The comparisons of MLS v2.2 ozone profiles show a general agreement at 5-10\% level with stratospheric profiles from satellite, balloon and ground-based data (Froidevaux et al., 2008; Jiang et al., 2007; Livesey et al., 2008). These results are expected to hold also for the v3.3 profiles (Livesey et al., 2011), which are used in the current study.

\section{Data analysis}

The planetary waves signatures in the ozone zonal distribution were investigated using the Fourier series analysis. The ozone longitudinal distribution in a certain latitude band (total ozone and number density or mixing ratio at a certain altitude or pressure) is represented by its Fourier series:

$f(\lambda)=\frac{a_{0}}{2}+\sum_{m=1}^{N}\left[a_{m} \cos (m \lambda)+b_{m} \sin (m \lambda)\right]$,

where $f(\lambda)$ is the ozone abundance at longitude $\lambda$ and $m$ is the wave number ranging from 1 to the largest harmonic $N$. The coefficients $a_{m}$ and $b_{m}$ were obtained fitting the model to the experimental data, by the least squares minimization.
As an example, Fig. 1 shows the results of the harmonic analysis using OMI total ozone data on 16 October 2010 with $N=5$. The quality of the fit was estimated using the coefficient of determination $R^{2}$, defined as the ratio of the modelled variance to the experimental variance. The analysis of $R^{2}$-statistics (applied to the whole data set) has shown that the components with wave numbers from 1 to 3 explain $\sim 95 \%$ of ozone variability. The components with wavenumber higher than 2 are often comparable or below the root mean square (RMS) of residuals (in both total ozone and profile measurements), thus the retrieved amplitudes of these harmonics cannot be reliable. In the following analyses, only the first two harmonics are considered.

The wave amplitudes, $A_{m}=\sqrt{a_{m}^{2}+b_{m}^{2}}$, averaged over a short time interval (daily for OMI total ozone and 3 days for MLS profiles) include both travelling and stationary wave components. The stationary component of the wave amplitude is isolated by applying the harmonic analysis to the monthly average longitudinal profile.

\section{Results}

\subsection{Total ozone zonal asymmetry}

The total ozone zonal asymmetry is caused by the displacement (due to planetary wave activity) of the low ozone polar air (ozone hole) toward the equator and of the mid-latitudinal ozone rich air, which accumulates outside the polar vortex, toward the pole. This is illustrated in Fig. 2 by the mean fields of OMI total ozone over the latitudes $30-90^{\circ} \mathrm{S}$ during October from 2005 to 2010 . The polar vortex is generally displaced in the $30^{\circ} \mathrm{E}-30^{\circ} \mathrm{W}$ area, while the ozone-rich air is located in the opposite region $\left(150-200^{\circ} \mathrm{E}\right)$, with respect to the South Pole.

In Fig. 3, the spring (September-October-November average) zonal extremes in OMI total ozone at $65^{\circ} \mathrm{S}$ (gray circle) are shown together with their longitudinal position during the period 2005-2010. The different years are labeled in red for the maxima and blue for the minima. The colors of the dots in Fig. 3 indicate the total ozone values.

During the last $6 \mathrm{yr}$, the zonal minimum remained below 250 DU, showing the largest values during 2009 and 2010. The position of the zonal minimum at $65^{\circ} \mathrm{S}$ ranged from $40^{\circ} \mathrm{W}$ (2009) and $40^{\circ} \mathrm{E}(2010)$. The zonal maximum was usually located between $150^{\circ} \mathrm{E}$ and $170^{\circ} \mathrm{W}$; in 2006 , when a low ozone maximum (less than $300 \mathrm{DU}$ ) was observed (see green point in Fig. 3 labeled with 06), the longitude of the maximum was about $170^{\circ} \mathrm{W}$.

\subsection{Wave components in the OMI total ozone zonal distribution}

The time evolution from August to December of the daily zonal distribution of the OMI total ozone at $65^{\circ} \mathrm{S}$ was compared with the wave components 1 and 2 every year from 

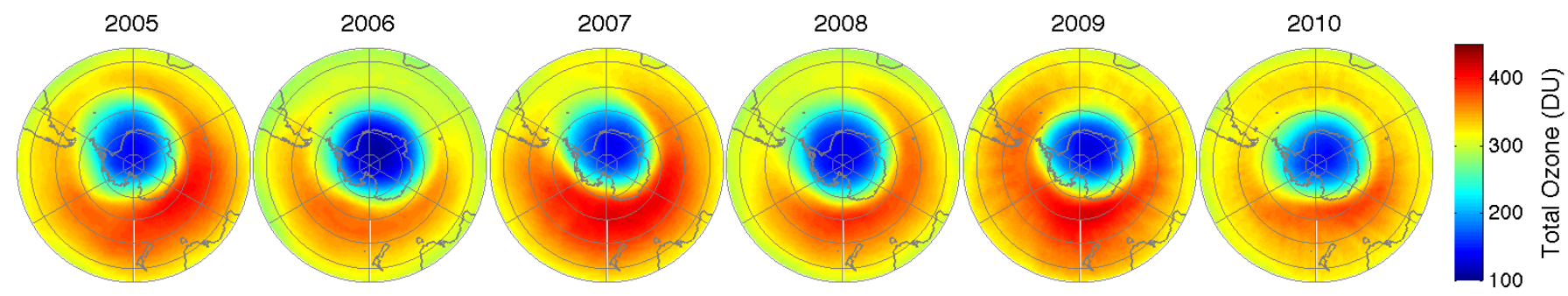

Fig. 2. October mean fields of OMI total ozone over the latitudes $30-90^{\circ} \mathrm{S}$. Red and blue colors refer to maximum and minimum total ozone values, respectively.

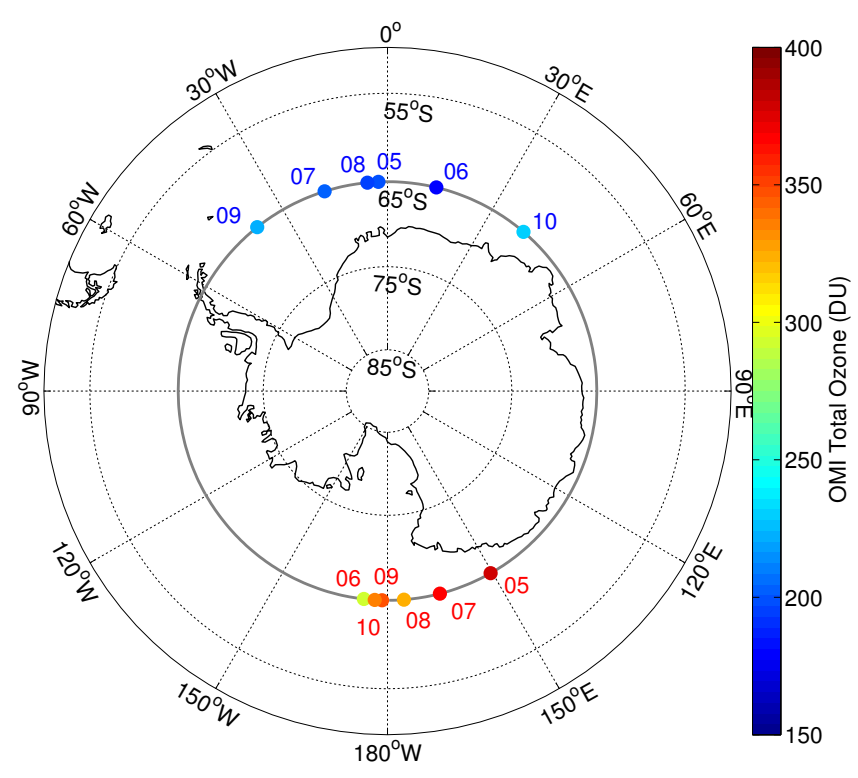

Fig. 3. OMI total ozone zonal extremes during spring 2005-2010 derived at $65^{\circ} \mathrm{S}$ (this latitude circle is marked with a gray solid line). The different years are labeled in red for the maxima and in blue for the minima. The colors of the dots indicate the total ozone values (red and blue colors refer to maximum and minimum total ozone values, respectively).

2005 to 2010 (Fig. 4). Both wave components show the highest activity during the period from September to November, with visible year-to-year variations. In 2006 and 2008, the wave activity started in mid-September, while it usually begins already in late-August. In 2010, the wave activity has been observed until mid-December with a westward phase change. The time evolution of the wave 1 component shows generally a weakening in early November, before increasing again at the end of the month. This decrease in wave 1 is often compensated by an increase in the wave 2 component. The wave 1 structure showed also an eastward motion (see the slope of the color stripes in Fig. 4) with periods of relative stability for example in November 2006 and during the whole spring 2008. In November 2009 a wave phase change caused a large westward displacement of the mini- mum/maximum structure. Wave 2 patterns showed a much stronger eastward transport with respect to wave 1.

The monthly mean amplitudes of waves 1 and 2 from September to November 2005-2010 are shown in Fig. 5 (stationary-plus-travelling in the upper panel and stationary in the middle panel). The ozone zonal mean, maximum and minimum values at $65^{\circ} \mathrm{S}$ are also shown (Fig. 5, lower panel). The variability on the monthly mean stationary-plustravelling wave amplitude is characterized with the standard deviation. The uncertainty of the stationary wave amplitude is derived from the uncertainties of the fitting coefficients $a_{m}$ and $b_{m}$, applied to the monthly zonal distribution. Only the wave numbers 1 and 2 showed an amplitude larger than the rms of residuals. The wave amplitude is larger in October than in the other months, reaching the value of $\sim 140 \mathrm{DU}$ $(\sim 45 \%)$ in wave 1 . Wave number 1 has generally the largest amplitude, except for November 2010, when the wave 2 amplitude exceeded the wave 1 amplitude by about $20 \mathrm{DU}$. Wave 1 is mainly a stationary wave, as observed comparing the travelling plus stationary and the stationary only for each month. The other wave numbers are otherwise mostly travelling waves; only during November 2009 and 2010 the wave 2 component showed a large stationary component, comparable to wave 1 . The wave 1 time yearly-evolution reproduces the mean and the maximum ozone zonal distribution, particularly during September and October, while the minimum values show sometimes a different behaviour (Fig. 5 - lower panels). This is related to both the position and the shape of the ozone hole and the amount of ozone reaching the polar region. The monthly relative amplitudes (not plotted here) show a year-to-year variability similar to the absolute values, with the wave 1 amplitude values ranging from $46 \%$ (October 2009) to $12 \%$ (November 2010). The observed yearto-year fluctuations in Antarctic total ozone may be partly influenced by the Quasi-Biennal Oscillation (QBO), leading to relatively low (high) ozone values occurring during the westerly (easterly) phase (Garcia and Solomon, 1987). 

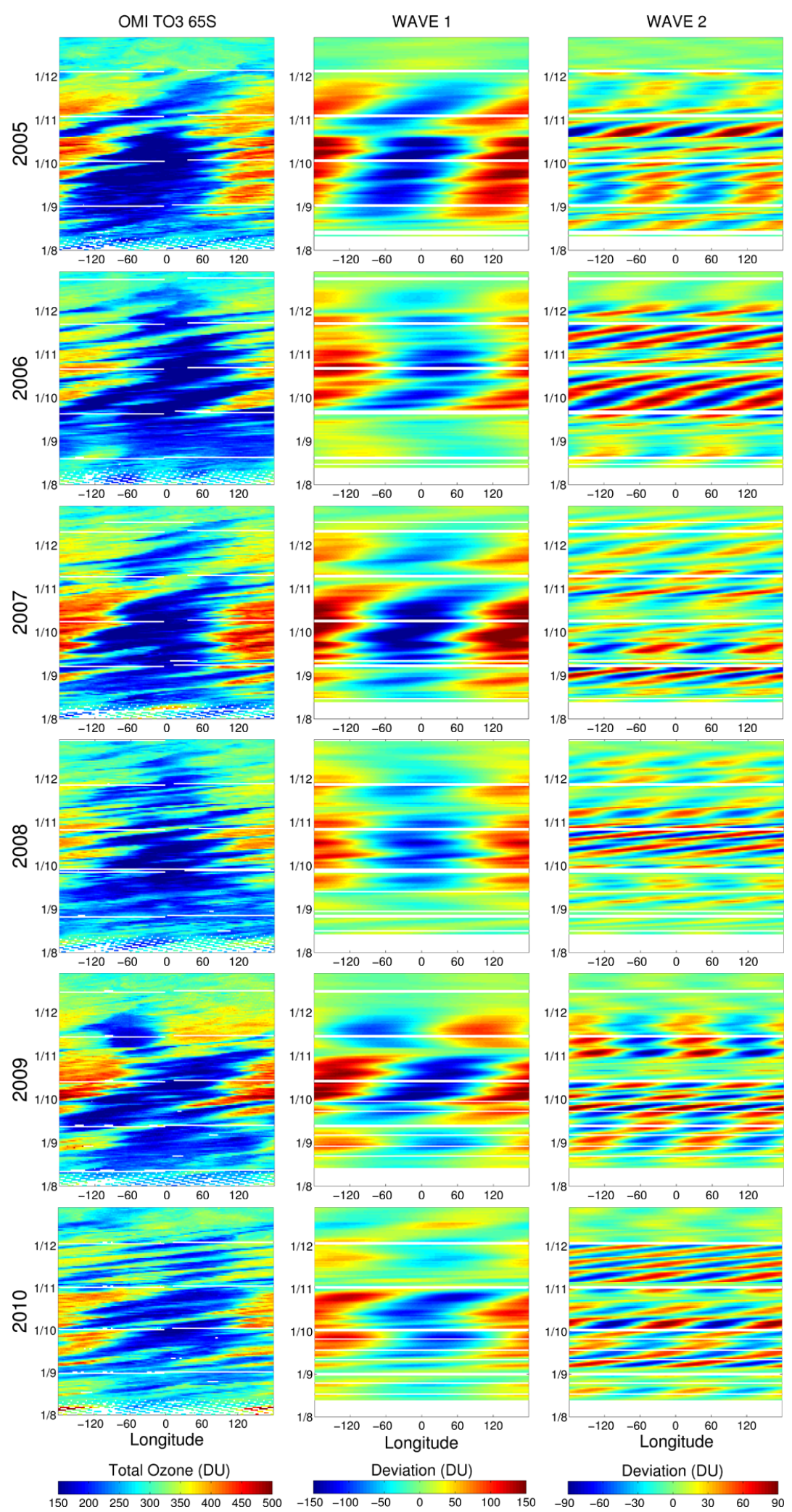

Fig. 4. Time-longitude diagrams of OMI total ozone (first column) at $65^{\circ} \mathrm{S}$ and the related wave components 1 and 2 (second and third column, respectively) during the period 1 August-31 December from 2005 (top panels) to 2010 (bottom panels). The red and blue colors in the plots of the first column refer to the maximum and minimum total ozone values, respectively. In the plots of the second and third columns, red colors refer to the maximum positive values and blue colors refer to the minimum negative values of the deviation from the zonal mean. 

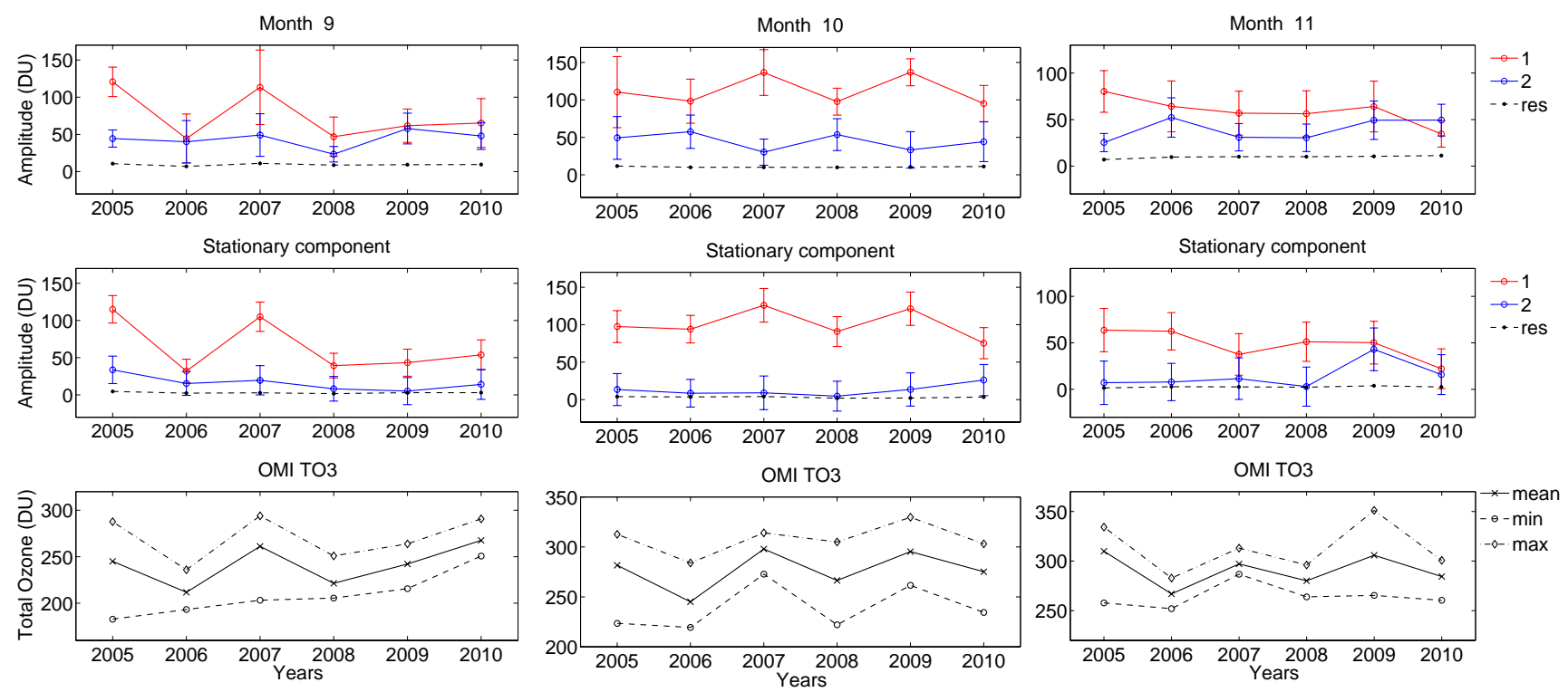

Fig. 5. Monthly wave amplitude from OMI total ozone during 2005-2010 (the columns from left to right represent September, October and November, respectively). Both travelling-plus-stationary and stationary-only components are shown (top and middle panels, respectively), together with the rms of the residuals (dashed line). The wave numbers 1 (red) and 2 (blue) are shown. The error bars in the top panels indicate the variability of wave amplitude. The error bars in the middle panels are derived from the fitting uncertainties of the monthly zonal distribution. In the bottom panels the monthly mean, maximum and minimum total ozone values are shown as solid, dot-dashed and dashed lines, respectively.

\subsection{Vertical extent of the zonal asymmetry}

\subsubsection{On the characterization of the ozone anomaly}

The distribution of ozone is defined by both chemical and dynamical processes, so is the vertical extent of the ozone asymmetry. At high latitudes in winter and spring, the ozone distribution is affected by the polar vortex disturbed by planetary waves. Therefore, the amplitude of ozone deviations from the zonal mean will depend on vertical coordinate (geometric altitude or pressure) and on quantity (number density or mixing ratio) used. This is illustrated in Fig. 6, which shows the ozone vertical distribution (upper panels) and the deviations from the zonal mean expressed in relative values (central panels) for ozone number density as a function of altitude and ozone mixing ratio as a function of pressure, as well as temperature and density deviations as a function of geometric altitude (lower panels). These plots are obtained from GOMOS ozone data in September 2003 at $55-65^{\circ} \mathrm{S}$ and ECMWF air density and temperature data at the locations of GOMOS occultations. (The time period and the latitude band are selected to have the best data coverage and quality.) As seen in Fig. 6, perturbations on ozone number density, which are of nearly constant amplitude up to $\sim 45 \mathrm{~km}$, are in phase with perturbations in air density above $25 \mathrm{~km}$, therefore the analogous perturbations on mixing ratio decrease more rapidly with altitude. It can be noticed the positive correlation of ozone and temperature perturbations below $\sim 35 \mathrm{~km}$ and their anti-correlation above $35-50 \mathrm{~km}$. This change in correlation is typical for transition from dynamically controlled lower stratosphere to the upper altitudes where chemical processes play a significant role in shaping the ozone distribution (Brasseur et al., 2005; Rood and Douglass, 1985; Smith, 1995).

\subsubsection{GOMOS observations of wave amplitudes}

Being presented in percents of a zonal mean value, the relative amplitudes of wave number 1 and 2 detected in GOMOS monthly mean ozone number density and mixing ratio in September (stationary components) are shown in Fig. 7. GOMOS retrievals provide ozone number density as a function of geometric altitude. For representation via mixing ratio at pressure levels, we used ECMWF air density and pressure values at the locations of GOMOS occultations.

The relative wave amplitudes are significantly larger in number density: they are 20-50\% for wave number 1 and $7-$ $15 \%$ for wave number 2 . Wave number 1 is well observed in ozone number density up to $60-65 \mathrm{~km}$ altitude, while wave number 2 amplitude exceeds significantly rms of residuals usually below $50-55 \mathrm{~km}$ (thus, fitted wave- 2 amplitudes are not reliable above these altitudes). In mixing ratio, relative wave amplitudes usually are smaller (7-30\% for wave number 1 and $5-10 \%$ for wave number 2), and they decay more 


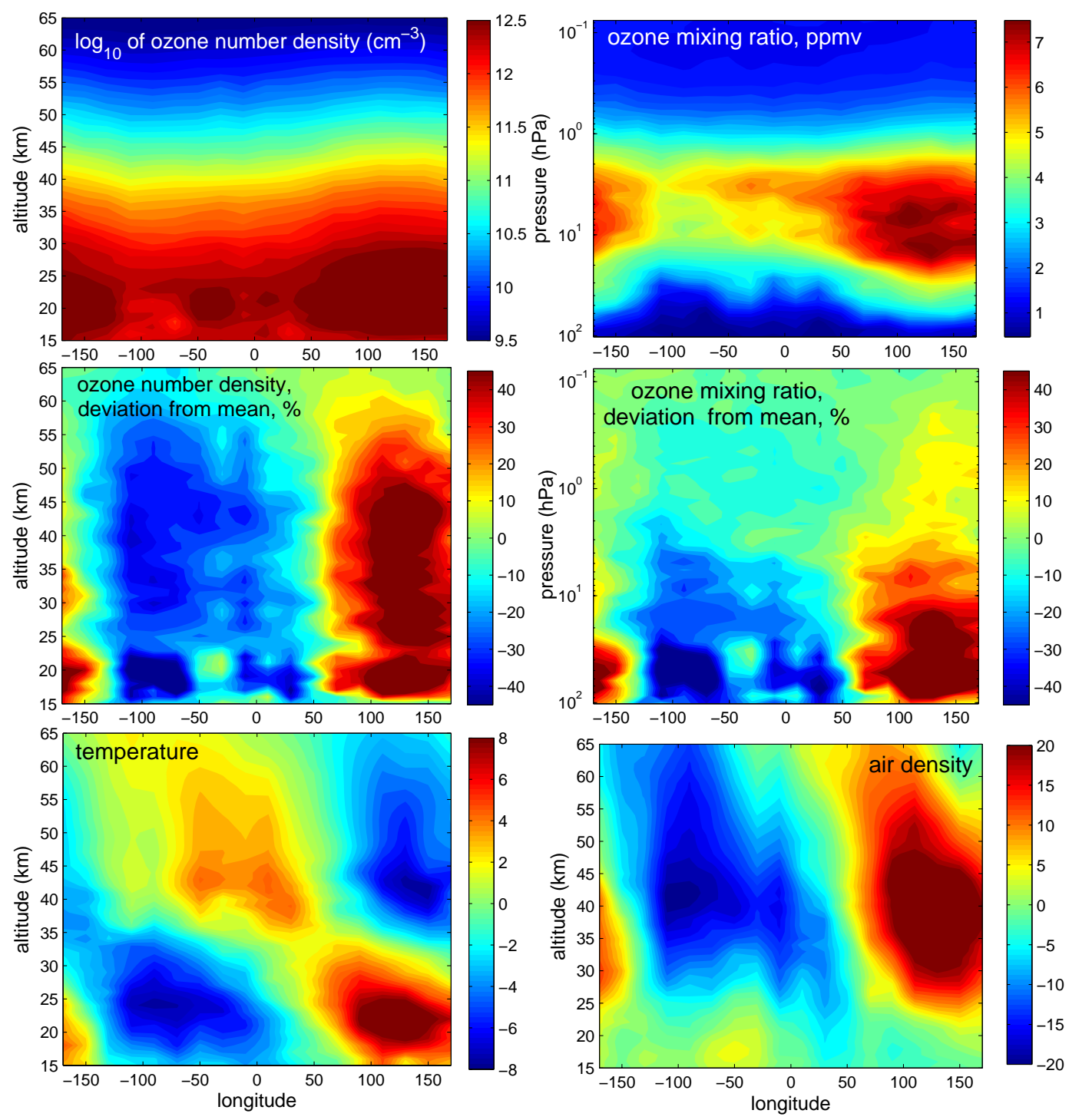

Fig. 6. Top: distribution of ozone number density (left) and mixing ratio (right) in September 2003 at $55-65^{\circ} \mathrm{S}$, as obtained from GOMOS measurements. Center: deviations from zonal mean (in \%) for ozone number density (left) and ozone mixing ratio (right). Bottom: deviations from zonal mean (in \%) for ECMWF temperature (left) and air density (right). Red colors refer to the maximum values and blue colors refer to the minimum values.

rapidly with altitude (decreasing pressure) than in case of ozone number density profiles.

Local minima can be observed in wave amplitude of ozone mixing ratio at altitudes $\sim 35-40 \mathrm{~km}$. These minima are even more pronounced in ozone mixing ratio presented as a function of geometric altitude (not shown). The location of these minima corresponds to the wave phase transition in temperature, and their appearance is explained by the structure of ozone and air density fields. The amplitudes of wave perturbations vary from year to year. They were especially large, up to $50 \%$ at altitudes $20-50 \mathrm{~km}$, in 2003 and in 2007 .

\subsubsection{MLS spatio-temporal observations of Antarctic ozone anomaly}

Due to a good coverage and temporal resolution, MLS data allow us to study the spatio-temporal evolution of the springtime Antarctic ozone anomaly. The harmonic analysis described in Sect. 3 has been applied to the MLS mixing ratio data at the pressure levels which are used in the MLS inversion algorithm.

Figure 8 shows the time series of relative amplitudes of wave 1 and 2 components detected in MLS ozone mixing ratio at $55-75^{\circ} \mathrm{S}$ in the southern spring seasons of years 2005-2010. These time series have been obtained by 

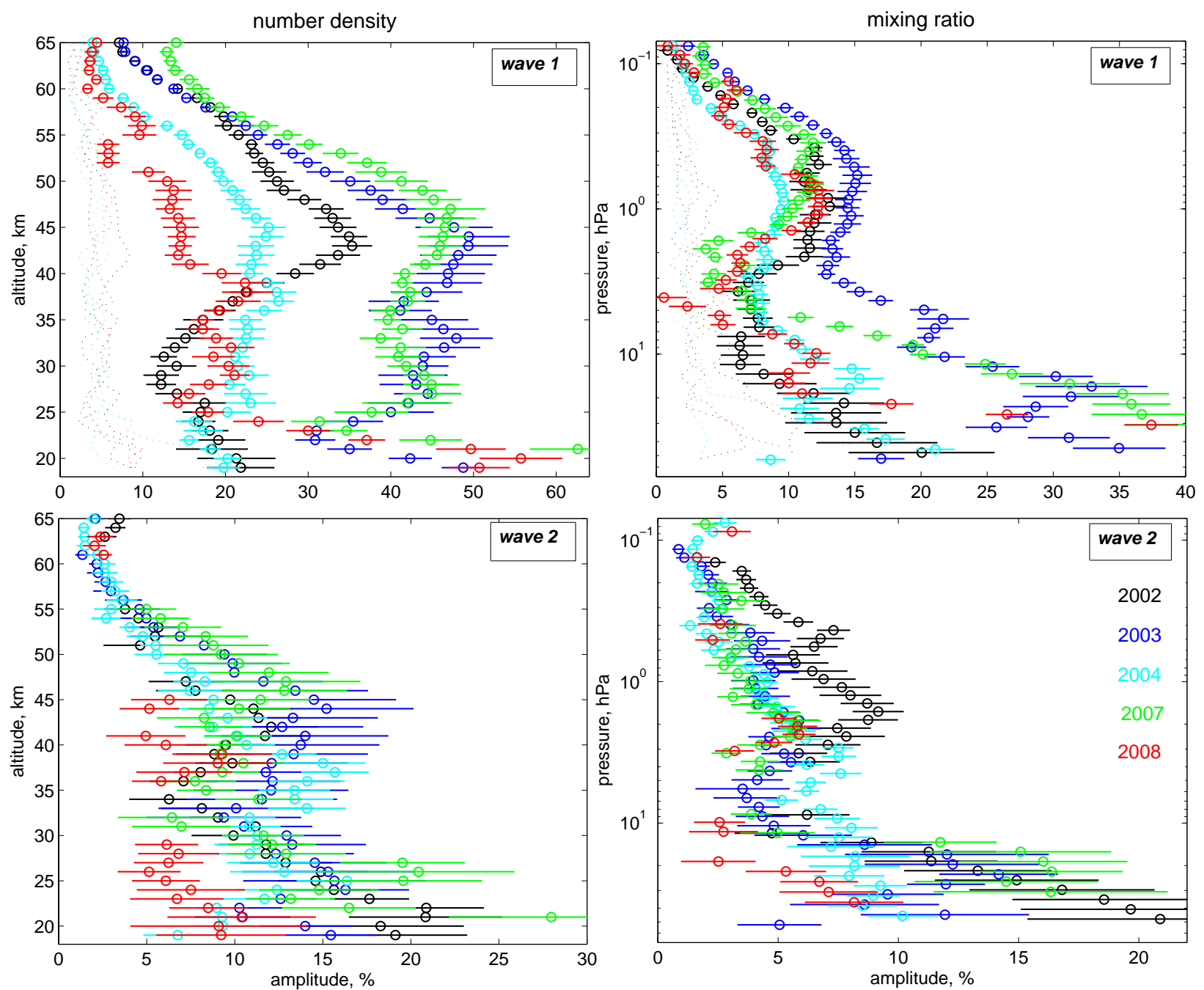

Fig. 7. Amplitude (in $\%$ of zonal mean) of wave 1 (top panels) and 2 (bottom panels) components in September monthly mean ozone profiles at $55-65^{\circ} \mathrm{S}$ in GOMOS ozone number density (left) and mixing ratio (right). Different years are denoted by different colors (2002 in black, 2003 in blue, 2004 in cyan, 2007 in green and 2008 in red). The missing years are due to lack of data. Error bars indicate the estimated uncertainty of the fitting. Dotted lines in the top subplots indicate rms of residuals. For wave 2 (bottom panels), only the amplitudes exceeding the rms of residuals are shown.

applying the harmonic analysis to the three-days running median data, thus they represent perturbations from both travelling and stationary planetary waves. Similarly to GOMOS data (Fig. 7), the wave amplitudes decay with the altitude, with maxima below $30 \mathrm{~km}$. MLS profiles of mixing ratio perturbations are shown up to $50 \mathrm{~km}$ for a better visibility, while visible perturbations in number density extend up to $60 \mathrm{~km}$. The wave 1 activity shows many similarities between the years, usually reaching maxima at $20 \mathrm{~km}$ towards the end of September and weakening in early November before strengthening again briefly at the end of November. Wave 2 activity is more irregular. It exhibits large short-term variations, in some cases coinciding with weakening wave 1 activity. This feature is observed also in OMI total ozone (Fig. 5). Local minima observed in GOMOS are also visible in MLS data at $35-40 \mathrm{~km}$ (see the downward propagating dark blue area located about 5-10 km above the red area in Fig. 8).

The altitude location of the largest amplitude decreases with time, as also the area of the strongest ozone depletion decreases in altitude. This happens when the ozone hole recovery starts (usually in October) and ozone-rich air masses appear and descend from about 50 to $100 \mathrm{hPa}$, replacing part of the ozone-depleted air (van Peet et al., 2009).

\section{Discussion and summary}

In this paper, the ozone column data from OMI and the ozone profiles from MLS and GOMOS in 2005-2010 have been used to characterize the zonal asymmetry during Antarctic 

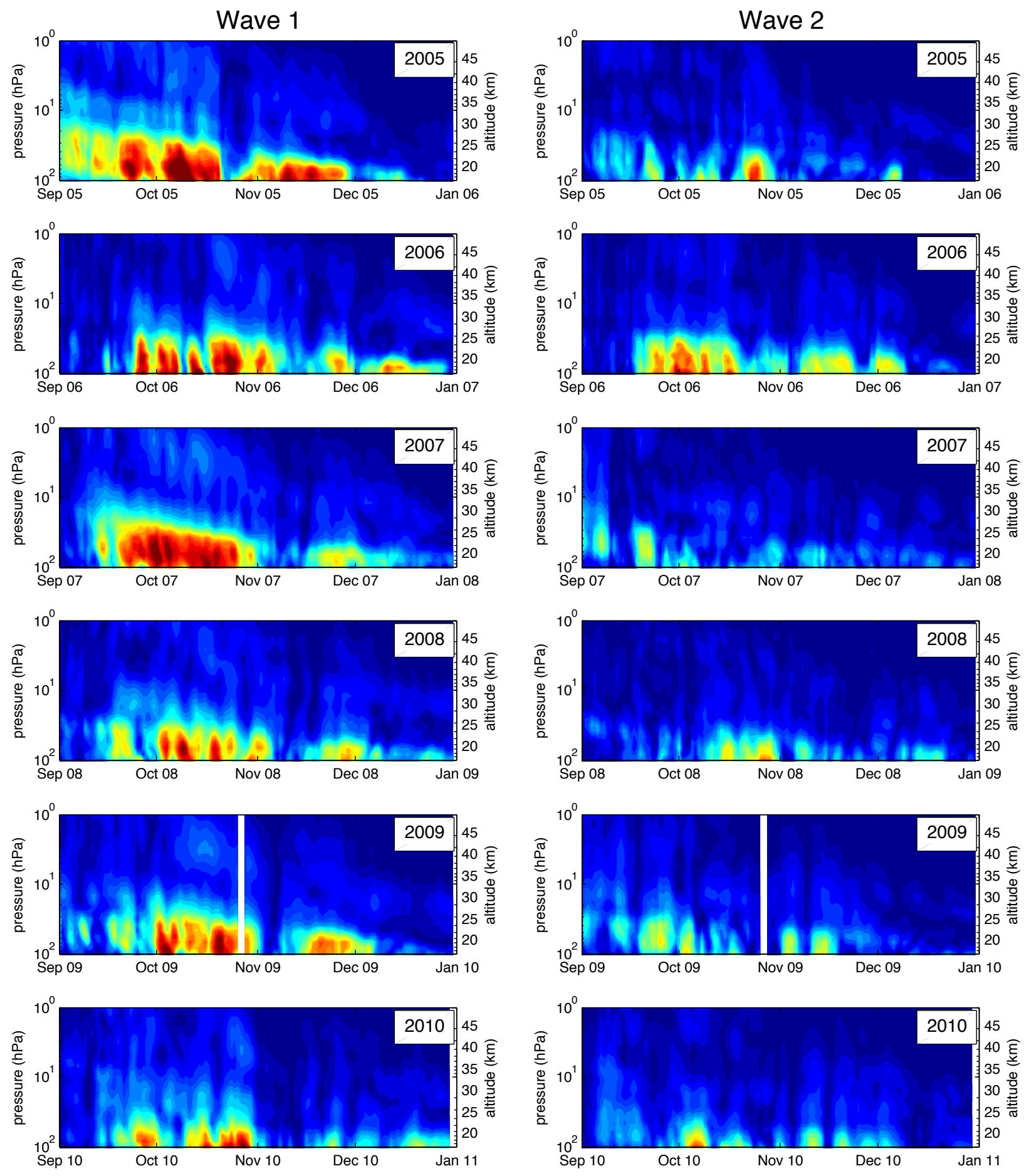

\begin{tabular}{lllllllllll}
0 & 5 & 10 & 15 & 20 & 25 & 30 & 35 & 40 & 45 & 50 \\
\hline & & & & Wave amplitude (\%) & & & & \\
\hline
\end{tabular}

Fig. 8. Time series of amplitudes (in $\%$ of zonal mean) of wave 1 and 2 components in MLS ozone mixing ratio at $55-75^{\circ} \mathrm{S}$ in SeptemberDecember, from 2005 (top panels) to 2010 (bottom panels). The harmonic analysis is applied to three-day running averages. The red and blue colors refer to the maximum and minimum amplitude values, respectively. 
spring, which is caused by the planetary wave-driven displacement of the polar vortex. The planetary wave amplitudes have been estimated applying the Fourier series analysis to the ozone longitudinal distributions. The analysis have confirmed that wave number 1 and 2 generally explain the largest part of the ozone zonal variability over Antarctica in spring. The wave activity is dominated by the quasistationary wave 1 component, while the wave 2 (usually showing smaller amplitude) is mainly an eastward travelling wave.

Overall, it can be noticed that all instruments show very similar spatio-temporal patterns in the wave activity. Some differences in the estimated wave amplitudes are due to the different geometry of measurement and the slightly different latitude ranges $\left(65^{\circ} \mathrm{S}\right.$ for OMI, 55-65 $\mathrm{S}$ for GOMOS and $55-75^{\circ} \mathrm{S}$ for MLS), which were selected to ensure the best spatio-temporal resolution for the harmonic analysis.

A detailed characterization of spatio-temporal distributions of springtime ozone over Antarctica has been provided. Our observations and findings can be summarized as follows.

1. A persistent zonal asymmetry over Antarctica has been observed during the last 6 southern spring seasons. This was caused by the planetary wave-driven displacement of the polar vortex, which moved the ozone hole to the sector $40^{\circ} \mathrm{E}-40^{\circ} \mathrm{W}$. At the same time, ozone-rich air occupied the area outside the vortex, with maximum levels in the sector $150^{\circ} \mathrm{E}-170^{\circ} \mathrm{W}$.

2. Both total ozone and profile data show that ozone asymmetry is usually observed from September to midDecember. The largest wave amplitude (up to $50 \%$ of zonal mean) at $\sim 65^{\circ} \mathrm{S}$ is observed in October.

3. The ozone profiles show that the asymmetry is extended to the whole stratosphere and that the wave amplitudes in ozone mixing ratio decay with altitude, with maxima (up to $50 \%$ ) below $30 \mathrm{~km}$. The altitude location of the largest amplitude decreases with time, as also the area of the strongest ozone depletion decreases in altitude.

4. Both OMI and MLS data show a local decrease of wave 1 amplitude in early November, which is accompanied with a local increase of wave 2 amplitude. This was particularly visible in November 2010 when the wave 2 amplitude exceeded wave 1 .

5. The interannual variations in wave amplitudes are similar in all the observations. The largest wave 1 activity was observed in 2005 and 2007 and the smallest in 2010.

All ozone climatologies created so far are based on zonal mean values. The results of our analyses show that Antarctic ozone asymmetry is a climatological feature. Ignoring this can lead to inaccuracies in different applications that rely on the climatological ozone values (climate simulations, retrievals from satellite measurements that need a priori information).

In several model studies it has been observed that the polar zonal asymmetry plays an important role in SH climate when estimating the future temperature trends (e.g. Crook et al., 2008; Waugh et al., 2009; Gillett et al., 2009). The information given in this paper about the planetary wave influence on the ozone distribution provides an important tool to compare the model results with independent satellite-based observations.

Acknowledgements. The authors are grateful to the Aura team and the GOMOS team for providing the data. This work was supported by the Academy of Finland (MIDAT and ASTREX projects) and ESA DRAGON-2 programme.

Edited by: W. Lahoz

\section{References}

Andrews, D. G., Holton, J. R., and Leovy, C. B.: Middle Atmospheric Dynamics, Academic Press, 1987.

Bertaux, J. L., Kyrölä, E., Fussen, D., Hauchecorne, A., Dalaudier, F., Sofieva, V., Tamminen, J., Vanhellemont, F., Fanton d'Andon, O., Barrot, G., Mangin, A., Blanot, L., Lebrun, J. C., Pérot, K., Fehr, T., Saavedra, L., Leppelmeier, G. W., and Fraisse, R.: Global ozone monitoring by occultation of stars: an overview of GOMOS measurements on ENVISAT, Atmos. Chem. Phys., 10, 12091-12148, doi:10.5194/acp-10-12091-2010, 2010.

Bhartia, P. K. and Wellemeyer, C. W.: TOMS-V8 total $\mathrm{O}_{3}$ algorithm, NASA Goddard Space Flight Center, Greenbelt, MD, OMI Algorithm Theoretical Basis Document, vol. II, 2002.

Brasseur, G. P. and Solomon, S.: Aeronomy of the Middle Atmosphere, 3rd edn., Springer, Dordrecht, 2005.

Crook, J. A., Gillett, N. P., and Keeley, S. P. E.: Sensitivity of Southern Hemisphere climate to zonal asymmetry in ozone, Geophys. Res. Lett., 35, L07806, doi:10.1029/2007GL032698, 2008.

Evtushevsky, O. M., Grytsai, A. V., Klekociuk, A. R., and Milinevsky, G. P.: Total ozone and tropopause zonal asymmetry during the Antarctic spring, J. Geophys. Res., 113, D00B06, doi:10.1029/2008JD009881, 2008.

Francis, G. and Salby, M.: Radiative influence of Antarctica on the polar night vortex, J. Atmos. Sci, 58, 1300-1309, 2001.

Froidevaux, L., Jiang, Y. B., Lambert, A., Livesey, N. J., Read, W. G., Waters, J. W., Browell, E. V., Hair, J. W., Avery, M. A., McGee, T. J., Twigg, L. W., Sumnicht, G. K., Jucks, K. W., Margitan, J. J., Sen, B., Stachnik, R. A., Toon, G. C., Bernath, P. F., Boone, C. D., Walker, K. A., Filipiak, M. J., Harwood, R. S., Fuller, R. A., Manney, G. L., Schwartz, M. J., Daffer, W. H., Drouin, B. J., Cofield, R. E., Cuddy, D. T., Jarnot, R. F., Knosp, B. W., Perun, V. S., Snyder, W. V., Stek, P. C., Thurstans, R. P. and Wagner, P. A.: Validation of Aura Microwave Limb Sounder stratospheric and mesospheric ozone measurements, J. Geophys. Res., 113, D15S20, doi:10.1029/2007JD008771, 2008.

Fusco, A. C. and Salby, M. L.: Interannual variations of total ozone and their relationship to variations of planetary wave activity, J. Climate, 12, 1619-1629, 1999. 
Gabriel, A., Körnich, H., Lossow, S., Peters, D. H. W., Urban, J., and Murtagh, D.: Zonal asymmetries in middle atmospheric ozone and water vapour derived from Odin satellite data 20012010, Atmos. Chem. Phys., 11, 9865-9885, doi:10.5194/acp-11-9865-2011, 2011.

Garcia, R. R. and Solomon, S.: A possible relationship between interannual variability in Antarctic ozone and the quasi-biennial oscillation, Geophys. Res. Lett., 14, 848-851, doi:10.1029/GL014i008p00848, 1987.

Gillett, N. P., Scinocca, J. F., Plummer, D. A., and Reader, M. C.: Sensitivity of climate to dynamically-consistent zonal asymmetries in ozone, Geophys. Res. Lett., 36, L10809, doi:10.1029/2009GL037246, 2009.

Grytsai, A., Grytsai, Z., Evtushevsky, A., Milinevsky, G., and Leonov, N.: Zonal wave numbers $1-5$ in planetary waves from the TOMS total ozone at $65^{\circ} \mathrm{S}$, Ann. Geophys., 23, 1565-1573, doi:10.5194/angeo-23-1565-2005, 2005.

Grytsai, A. V., Evtushevsky, O. M., Agapitov, O. V., Klekociuk, A. R., and Milinevsky, G. P.: Structure and long-term change in the zonal asymmetry in Antarctic total ozone during spring, Ann. Geophys., 25, 361-374, doi:10.5194/angeo-25-361-2007, 2007.

Hartmann, D. L., Mechoso, C. R., and Yamazaki, K.: Observations of wave mean flow interaction in Southern Hemisphere, J. Atmos. Sci., 41, 351-362, 1984.

Hio, Y. and Yoden, S.: Quasi-periodic variations of the polar vortex in the Southern Hemisphere due to wave-wave interaction, J. Atmos. Sci., 61, 2510-2527, 2004.

Holton, J. R., Haynes, P. H., McIntyre, M. E., Douglass, A. R., Rood, R. B., and Pfister, L.: Stratosphere-troposphere exchange, Rev. Geophys., 33, 403-439, doi:10.1029/95RG02097, 1995.

Jiang, Y. B., Froidevaux, L., Lambert, A., Livesey, N. J., Read, W. G., Waters, J. W., Bojkov, B., Leblanc, T., McDermid, I. S., Godin-Beekman, S., Filipiak, M. J., Harwood, R. S., Fuller, R. A., Daffer, W. H., Drouin, B. J., Cofield, R. E., Cuddy, D. T., Jarnot, R. F., Knosp, B. W., Perun, V. S., Schwartz, M. J., Snyder, W. V., Stek, P. C., Thurstans, R. P., Wagner, P. A., Allaart, M., Andersen, S. B., Bodeker, G., Calpini, B., Claude, H., Coetzee, G., Davies, J., DeBacker, H., Dier, H., Fujiwara, M., Johnson, B., Kelder, H., Leme, N. P., König-Langlo, G., Kyrö, E., Laneve, G., Fook, L. S., Merrill, J., Morris, G., Newchurch, M., Oltmans, S., Parrondos, M. C., Posny, F., Schmidlin, F., Skrivankova, P., Stubi, R., Tarasick, D. W., Thompson, A. M., Thouret, V., Viatte, P., Vomel, H., von der Gathen, P., Yela, M., and Zablocki, G.: Validation of Aura Microwave Limb Sounder Ozone by ozonesonde and lidar measurements, J. Geophys. Res., 112, D24S34, doi:10.1029/2007JD008776, 2007.

Kyrölä, E., Tamminen, J., Sofieva, V., Bertaux, J. L., Hauchecorne, A., Dalaudier, F., Fussen, D., Vanhellemont, F., Fanton d'Andon, O., Barrot, G., Guirlet, M., Mangin, A., Blanot, L., Fehr, T., Saavedra de Miguel, L., and Fraisse, R.: Retrieval of atmospheric parameters from GOMOS data, Atmos. Chem. Phys., 10, 1188111903, doi:10.5194/acp-10-11881-2010, 2010.

Livesey, N. J. and Snyder, W. V.: EOS MLS Retrieval Processes Algorithm Theoretical Basis, Pasadena, California, available at: http://mls.jpl.nasa.gov/data/eos_algorithm_atbd.pdf, 2004.

Livesey, N. J., Filipiak, M. J., Froidevaux, L., Read, W. G., Lambert, A., Santee, M. L., Jiang, J. H., Pumphrey, H. C., Waters, J. W., Cofield, R. E., Cuddy, D. T., Daffer, W. H., Drouin, B. J., Fuller, R. A., Jarnot, R. F., Jiang, Y. B., Knosp, B. W., Li,
Q. B., Perun, V. S., Schwartz, M. J., Snyder, W. V., Stek, P. C., Thurstans, R. P., Wagner, P. A., Avery, M., Browell, E. V., Cammas, J. P., Christensen, L. E., Diskin, G. S., Gao, R. S., Jost, H. J., Loewenstein, M., Lopez, J. D., Nédélec, P., Osterman, G. B., Sachse, G. W., and Webster, C. R.: Validation of Aura Microwave Limb Sounder $\mathrm{O}_{3}$ and $\mathrm{CO}$ observations in the upper troposphere and lower stratosphere, J. Geophys. Res., 113, D15S02, doi:10.1029/2007JD008805, 2008.

Livesey, N. J., Read, W. J., Froidevaux, L., Lambert, A., Manney, G. L., Pumphrey, H. C., Santee, M. L., Schwartz, M. J., Wang, S., Cofield, R. E., Cuddy, D. T, Fuller, R. A., Jarnot, R. F., Jiang, J. H., Knosp, B. W., Stek, P. C., Wagner, P. A., and Wu, D. L.: Earth Observing System (EOS) Aura Microwave Limb Sounder (MLS) Version 3.3 Level 2 data quality and description document, JPL D-33509, California Institute of Technology, Pasadena, California, 18 January, 2011.

Mechoso, C. R., Hartmann, D. L., and Farrara, J. D.: Climatology and interannual variability of wave, mean-flow interaction in the southern hemisphere, J. Atmos. Sci., 42, 2189-2206, 1985.

Rood, R. and Douglass, A. R.: Interpretation of Ozone Temperature Correlations 1. Theory, J. Geophys. Res., 90, 5733-5743, 1985.

Smith, A. K.: Numerical simulation of global variations of temperature, ozone, and trace species in the stratosphere, J. Geophys. Res., 100, 1253-1269, doi:10.1029/94JD02395, 1995.

Sofieva, V. F., Tamminen, J., Haario, H., Kyrölä, E., and Lehtinen, M.: Ozone profile smoothness as a priori information in the inversion of limb measurements, Ann. Geophys., 22, 3411-3420, doi:10.5194/angeo-22-3411-2004, 2004.

Sofieva, V. F., Kyrölä, E., Verronen, P. T., Seppälä, A., Tamminen, J., Marsh, D. R., Smith, A. K., Bertaux, J.-L., Hauchecorne, A., Dalaudier, F., Fussen, D., Vanhellemont, F., Fanton d'Andon, O., Barrot, G., Guirlet, M., Fehr, T., and Saavedra, L.: Spatiotemporal observations of the tertiary ozone maximum, Atmos. Chem. Phys., 9, 4439-4445, doi:10.5194/acp-9-4439-2009, 2009.

Sofieva, V. F., Kalakoski, N., Verronen, P. T., Päivärinta, S.-M., Kyrölä, E., Backman, L., and Tamminen, J.: Polar-night $\mathrm{O}_{3}$, $\mathrm{NO}_{2}$ and $\mathrm{NO}_{3}$ distributions during sudden stratospheric warmings in 2003-2008 as seen by GOMOS/Envisat, Atmos. Chem. Phys., 12, 1051-1066, doi:10.5194/acp-12-1051-2012, 2012.

Solomon, S.: Stratospheric ozone depletion: a review of concepts and history, Rev. Geophys., 37, 275-316, doi:10.1029/1999RG900008, 1999.

Tamminen, J., Kyrölä, E., and Sofieva, V. F.: Does prior information improve measurements?, in: Occultations for Probing Atmosphere and Climate - Science from the OPAC-1 Workshop, edited by: Kirchengast, G., Foelsche, U., and Steiner, A. K., 8798, Springer Verlag, 2004.

Tamminen, J., Kyrölä, E., Sofieva, V. F., Laine, M., Bertaux, J.-L., Hauchecorne, A., Dalaudier, F., Fussen, D., Vanhellemont, F., Fanton-d'Andon, O., Barrot, G., Mangin, A., Guirlet, M., Blanot, L., Fehr, T., Saavedra de Miguel, L., and Fraisse, R.: GOMOS data characterisation and error estimation, Atmos. Chem. Phys., 10, 9505-9519, doi:10.5194/acp-10-9505-2010, 2010.

van Peet, J. C. A., van $\operatorname{der}$ A, R. J., de Laat, A. T. J., Tuinder, O. N. E., Könïg-Langlo, G., and Wittig, J.: Height resolved ozone hole structure as observed by the Global Ozone Monitoring Experiment-2, Geophys. Res. Lett., 36, L11816, doi:10.1029/2009GL038603, 2009. 
Waters, J. W., Froidevaux, L., Harwood, R. S., Jarnot, R. F., Pickett, H. M., Read, W. G., Siegel, P. H., Cofierld, R. E., Filipiak, M. J., Flower, D. A., Holden, J. R., Lau, J. K., Livesey, N. J., Manney, J. L., Pumphrey, H. C., Santee, M. L., Wu, D. L., Cuddy, D. T., Lay, R. R., Loo, M. S., Perun, V. S., Schwartz, M. J., Stek, P. C., Thurstans, R. P., Boyles, M. A., Chandra, K. M., Chavez, M. C., Gun-Shing Chen, Chudasama, B. V., Dodge, R., Fuller, R. A., Girard, M. A., Jiang, J. H., Yibo Jiang, Knosp, B. W., LaBelle, R. C., Lam, J. C., Lee, K. A., Miller, D., Oswald, J. E., Patel, N. C., Pukala, D. M., Quintero, O., Scaff, D. M., Van Snyder, W., Tope, M. C., Wagner, P. A., and Walch, M. J.: The Earth Observing System Microwave Limb Sounder (EOS MLS) on the Aura satellite, IEEE T. Geosci. Remote, 44, 1075-1092, doi:10.1109/TGRS.2006.873771, 2006.
Waugh, D. W., Oman, L., Newman, P. A., Stolarski, R. S., Pawson, S., Nielsen, J. E., and Perlwitz, J.: Effect of zonal asymmetries in stratospheric ozone on simulated Southern Hemisphere climate trends, Geophys. Res. Lett., 36, L18701, doi:10.1029/2009GL040419, 2009. 